his failure could be controlled medically for three months to allow the defect to develop firm fibrous margins, but within five weeks he deteriorated. At operation a defect near the apex of the right ventricle was repaired with a Teflon patch, faced with pericardium.

\section{Discussion}

At a time when the incidence of high-speed road-traffic accidents is increasing, we have detailed three instances where, following resuscitation, injury to the heart and great vessels became apparent. In the fourth case the signs developed 24 hours after the accident. Rice and Wittstruck (1951) stated that the aorta ruptures because the thoracic part continues to travel forwards while the arch is tethered. Greendyke (1966) reviewing the results of necropsies in 218 car accidents, found aortic rupture in $16 \%$. He included these in a detailed review of 42 cases. The commonest site of rupture of the thoracic aorta ( $50 \%$ of cases) was the isthmus, immediately distal to the origin of the subclavian artery, at the insertion of the ductus arteriosus. The aortic hiatus of the diaphragm and the ascending aorta just superior to the valve were found to be the other important sites. In 14 cases aortic rupture was the major cause of death, but in 28 cases it was accompanied by other serious and potentially lethal trauma. Thirty-four cases had a simple laceration while the remaining eight had multiple tears. Complete transection occurred in 20 cases. Where patients were involved in road-traffic accidents most of the car occupants were young adults, while pedestrians were mostly past middle life.

In the very early cases it could be argued that angiography to delineate the tear would introduce delay and the dangers of further extension trauma. In cases diagnosed some time from the original accident the argument for full investigation is very strong. In accident departments the possibility of trauma to the aorta should be considered. Patients complain of chest pain and shortness of breath. $X$-ray films, including a penetrated film, should be taken, even if there are no external signs of trauma. A widened upper mediastinum is a suspicious sign. A further $x$-ray film may be necessary after two to three hours if there is doubt or the clinical state demands it. The electrocardiogram may show signs of myocardial damage, a previously known axis may be changed, or a low-voltage may suggest tamponade.

Traumatic mitral incompetence seems to be a rare injury. McLaughlin et al. (1964) surveyed 18 cases from the English literature. In discussion, a review of 546 cases of blunt trauma was quoted, in which no case of isolated mitral valve disease is listed. In mitral valve injury papillary muscle rupture or avulsion is the usual lesion. The patient is shocked, dyspnoeic, cyanosed, and has chest pain. Murmurs may or may not be present at this stage. If failure is absent then it soon develops, while if the patient does not die in the first hour then he is able to compensate and the subsequent course is that of valvular heart disease. This is in contrast to patients with post-infarctive papillary muscle in incompetence, who generally deteriorate rapidly (Craddock and Mahe, 1953) because of associated myocardial damage. In the diagnosis serial $x$-ray films help, especially if a pre-trauma film is available. Post-traumatic pulmonary venous congestion is the rule. The electrocardiogram is abnormal but not specific.

Reviewing traumatic ventricular septal defect Pollock et al. (1952) found 12 cases of isolated septal rupture. Cary et al. (1958) described the case (among four) of a patient who lived 52 hours and had no external signs of crush injury, bruising, or fractured ribs. The electrocardiogram had shown changes compatible with muscle death, injury, and ischaemia, and a conduction defect suggestive of right bundle-branch block. The phase of ventricular systole when the injury occurred was important, and this has also been shown experimentally (Bright and Beck, 1935). Another possible mechanism of septal rupture is infarction following occlusive trauma to the coronary vessels.

Whatever the mechanism for these injuries, we feel it is important that the processes described above should be borne in mind when dealing with high-speed trauma, as following the initial resuscitation period such conditions are often apparent, and with the advances of surgical technique a total correction can often be performed.

We wish to thank Dr. Walter Somerville for his valuable criticism and the photographic and medical illustration departments of the Institute of Urology for preparing the photographs and diagrams.

\section{REFERENCES}

Bright, E. F., and Beck, C. S. (1935). American Heart foumal, 10, 293. Cary, F. H., Hurst, J. W., and Arentzen, W. R. (1958). New England fournal of Medicine, $\mathbf{2 5 8}, 355$

Craddock, W. L. and Mahe, G. A. (1953). Fournal of the American Medical Association, 151, 884

Greendyke, R. M. (1966). Fournal of the American Medical Association, $195,527$.

McLaughlin, J. S., Cowley, R. A., Smith, G., and Matheson, N. A (1964). Fournal of Thoracic and Cardiovascular Surgery, 48, 261. Pollock, B. E., Markelz, R. A., and Shuey, H. E. (1952). American Heart fournal, 43, 273.

Rice, W. G., and Wittstruck, K. P. (1951). Fournal of the American Medical Association, 147, 915 .

\title{
Effect of Pregnancy on Sebum Excretion
}

\author{
J. L. BURTON, ${ }^{*}$ B.SC., M.R.C.P. ; W. J. CUNLIFFE, ${ }^{*}$ B.SC., M.R.C.P. ; D. G. MILLAR,† $\|$ F.R.C.s., M.R.c.o.G. \\ SAM SHUSTER, $\ddagger$ PH.D., F.R.C.P.
}

British Medical fournal, 1970, 2, 769-771

\begin{abstract}
Cummary: Sebum excretion rates from forehead skin were measured serially during and after pregnancy in 10 normal women. Only minor fluctuations occurred during the middle and last trimesters of pregnancy, but there was a pronounced decrease in the postpartum period.
\end{abstract}

\footnotetext{
*Senior Registrar, University Department of Dermatology, Royal Victoria Infirmary, Newcastle upon Tyne.

+ Senior Lecturer, University Department of Obstetrics, Princess Mary Maternity Hospital, Newcastle upon Tyne.

₹ Professor of Dermatology, University of Newcastle upon Tyne.

Now Professor of Human Reproduction and Obstetrics, Southampton General Hospital, Southampton.

$\S$ Now Consultant Dermatologist, the General Infirmary, Leeds.
}

Probably a powerful sebotrophic factor is present in pregnancy, but its nature is conjectural.

\section{Introduction}

Some of the factors controlling human sebaceous gland activity have been identified by observing the effect of exogenous hormones given to normal and castrated subjects (Strauss and Pochi, 1963). Little is known, however, of the sebaceous response to some more common endocrinological upheavals such as those due to pregnancy. The flurry of metabolic and 
hormonal activity which accompanies pregnancy makes its effect on the sebaceous gland unpredictable. We have therefore made serial measurements of the sebum excretion rate during and after pregnancy in normal subjects.

\section{Methods}

Sebum excretion rates from forehead skin in 10 pregnant women were measured serially by the method of Strauss and Pochi (1961) as modified by Cunliffe and Shuster (1969). The initial collection was made at the first antenatal clinic visit when the subjects were 12 to 16 weeks pregnant, and measurements were taken at four-weekly intervals thereafter until term. Another collection was made three days after delivery and one or two measurements were taken in each subject 5 to 20 weeks later.

All sebum collections were made in the morning to annul the effect of circadian variation in sebaceous activity (Burton et al., (1970), and possible seasonal variations in sebaceous activity were compensated so far as was possible by staggering the initial observations over a period of six months. All collections were performed at a room temperature of about $23^{\circ} \mathrm{C}$. and forehead skin temperatures were measured by a thermocouple (Light Laboratories) immediately after many of the later collections, following our observation that skin temperature affects the sebum excretion rate (Cunliffe, Burton, and Shuster, 1969, unpublished).

None of the subjects applied any topical medicament to the face during this study, though the use of cosmetics was allowed except for 24 hours preceding cach sebum collection. No drugs other than laxatives, antacids, and haematinics were given during the pregnancy. The placental weight at term was recorded and the duration of breast-feeding and contraceptive methods after pregnancy were noted.

The women were examined for acne lesions at each collection period, and their subjective observations on any possible facial skin changes were noted.

\section{Results}

The individual sebum excretion rates are given in the Table. To facilitate comparison the rates in each subject have been converted to a percentage of the initial sebum excretion rate measured in that subject. The mean percentage sebum excretion rates during and after pregnancy are shown in the Chart. There was a slight progressive decrease in sebum excretion towards the end of the second trimester of pregnancy; this decrease (to $79 \% \pm 7$ ) was significant at $28-32$ weeks (for the paired differences $t=3.3, \mathrm{P}<0.02$ ). Thereafter the mean sebum excretion rate increased to the initial level until after the end of pregnancy. There was no change immediately after delivery, but by 5 to 14 weeks later the rate had

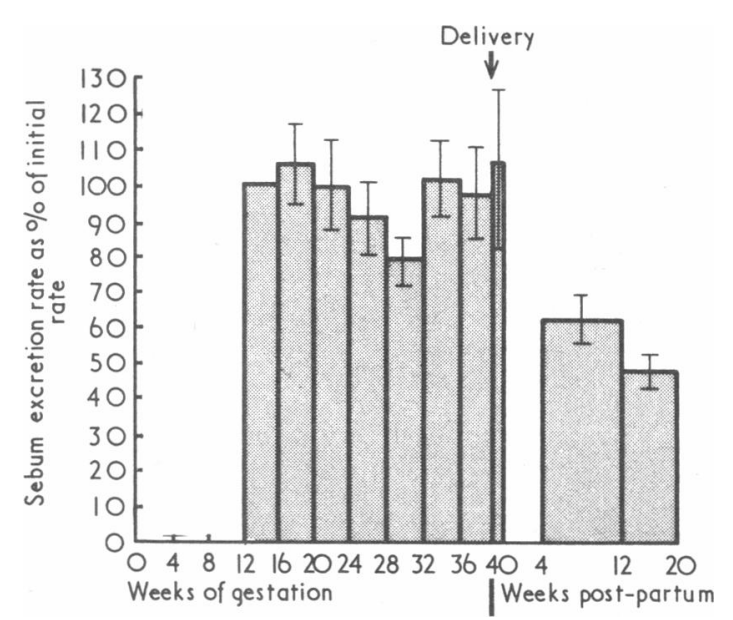

Mean Sebum Excretion Rates \pm 1 S.E. During and After Pregnancy.

fallen to $62 \% \pm 7$. This decrease was highly significant (for the paired differences $t=5.1, \mathrm{P}<0.001)$. In view of this unex- 0 pected finding the sebum excretion rate was measured again $\vec{N}$ six weeks later in four subjects and a further slight decrease was found. Seven of the 10 subjects had mild acne lesions at some stage of pregnancy, and though the activity of these lesions fluctuated throughout pregnancy no consistent subjective or objective changes occurred.

All subjects had full-term deliveries of live babies. The duration of breast-feeding did not appear to affect the postpartum fall in sebum excretion rate. Subject 1 breast-fed until after the final collection, and Subjects 2, 3, 4, 5, 6, and 7 breast-fed for one to four weeks; and in Subjects 8, 9, and 10 lactation was suppressed by oral stilboestrol $(90 \mathrm{mg}$. given in divided doses over seven days). Subjects 1 and 6 had taken an oral contraceptive for two weeks before their final collection. The mean skin temperature recorded in the last trimester of pregnancy $\left(34.7^{\circ} \mathrm{C} . \pm 0.1\right)$ was significantly higher than the mean skin temperature at the later postpartum collection $\left(34.1^{\circ} \mathrm{C} . \pm 0 \cdot 1\right)(t=4 \cdot 0, \mathrm{P}<0.005)$.

\section{Discussion}

Our study has shown changes in sebum excretion during and after pregnancy. The biological significance of the decreased sebum excretion towards the end of the second trimester is dubious, since the decrease is not great and depends for its statistical significance on a single set of observations at about 29 weeks. Apart from this minor fluctuation the sebum excretion rate is relatively constant during the middle and last trimesters of pregnancy.

By contrast, sebum excretion shows a pronounced decrease in the postpartum period. Sebum excretion is known to be influenced by changes in skin temperature (Cunliffe, Burton,

Sebum Excretion Rates ( $\mu$ g./sq.cm./min.)

\begin{tabular}{|c|c|c|c|c|c|c|c|c|c|c|c|c|}
\hline \multirow{2}{*}{ Subject } & \multirow{2}{*}{ Age } & \multicolumn{7}{|c|}{ Duration of Gestation (Weeks) } & \multirow{2}{*}{$\begin{array}{l}\text { Mean Rate } \\
\text { During } \\
\text { Pregnancy }\end{array}$} & \multicolumn{3}{|c|}{ Post-partum } \\
\hline & & $12-16$ & $16-20$ & $20-24$ & $24-28$ & $28-32$ & $32-36$ & $36-40$ & & 3 Days & 5-14 Weeks & 14-20 Weeks \\
\hline $\begin{array}{c}1 \\
2^{*} \\
3 \\
4^{*} \\
5^{*} \\
6 \\
7^{*} \\
8^{*} \\
9^{*} \\
10^{*}\end{array}$ & $\begin{array}{c}24 \\
24 \\
31 \\
22 \\
21 \\
20 \\
23 \\
25 \\
21 \\
31 \\
\text { Mean } \\
\text { n.E. }\end{array}$ & $\begin{array}{l}0.49 \\
= \\
0.36 \\
0.56 \\
0.46 \\
0.65 \\
1.63 \\
1.30 \\
1.16 \\
0.82 \\
8 \\
0.17\end{array}$ & $\begin{array}{l}0.50 \\
0.30 \\
0.40 \\
0.99 \\
0.49 \\
0.44 \\
2.00 \\
1.36 \\
0.65 \\
0.79 \\
9 \\
0.19\end{array}$ & $\begin{array}{c}0.57 \\
0.92 \\
0.15 \\
0.65 \\
0.58 \\
0.43 \\
0.38 \\
2.23 \\
1.00 \\
0.89 \\
0.78 \\
10 \\
0.18\end{array}$ & $\begin{array}{l}0.55 \\
0.86 \\
0.35 \\
0.35 \\
0.54 \\
0.41 \\
0.29 \\
2.46 \\
0.95 \\
0.65 \\
0.78 \\
9 \\
0.22\end{array}$ & $\begin{array}{l}0.36 \\
0.90 \\
0.29 \\
0.48 \\
0.38 \\
0.37 \\
1.82 \\
0.85 \\
0.59 \\
0.67 \\
9 \\
0.16\end{array}$ & $\begin{array}{l}0.61 \\
0.97 \\
-1.49 \\
0.44 \\
0.68 \\
0.32 \\
1.91 \\
0.96 \\
0.91 \\
0.81 \\
9 \\
0.16\end{array}$ & $\begin{array}{c}0.63 \\
0.86 \\
0.37 \\
0.20 \\
0.38 \\
- \\
2.27 \\
\overline{0.80} \\
0.79 \\
7 \\
0.26\end{array}$ & $\begin{array}{c}0.53 \pm 0.03 \\
0.90 \pm 0.02 \\
0.27 \pm 0.06 \\
0.39 \pm 0.05 \\
0.56 \pm 0.08 \\
0.48+0.04 \\
0.41 \pm 0.05 \\
2.05+0.11 \\
1.07+0.08 \\
0.81+0.07 \\
0.75 \\
10 \\
0.16\end{array}$ & $\begin{array}{l}0.85 \\
- \\
0.73 \\
0.31 \\
0.53 \\
0.40 \\
2 \cdot 17 \\
0.84 \\
0.32 \\
0.77 \\
8 \\
0.21\end{array}$ & $\begin{array}{c}0.26 \\
0.60 \\
0.21 \\
0.39 \\
0 \cdot 22 \\
0.42 \\
0.21 \\
0.80 \\
0.62 \\
0.75 \\
0 \cdot 45 \\
10 \\
0.07\end{array}$ & $\begin{array}{c}0.20 \\
= \\
= \\
0 \cdot 25 \\
0.25 \\
-- \\
- \\
1.55 \\
0.71 \\
0 \cdot 43 \\
4 \\
0 \cdot 12\end{array}$ \\
\hline
\end{tabular}

*Clinical acne lesions 
and Shuster, 1969, unpublished observations), but the decrease is far greater than can be accounted for by the small decrease in skin temperature we observed. The change in sebum excretion rate in the postpartum period may have been due either to an increased rate during pregnancy or to a decrease following delivery, or both. The fact that the postpartum rate was still low at 12 to 20 weeks after pregnancy, when most of the endocrine changes are likely to have reverted to normal, suggests that the rate of sebum excretion is somewhat increased during pregnancy compared with the rate before conception.

Oestrogens in doses as small as $0.25 \mathrm{mg}$. of ethinyloestradiol daily by mouth will inhibit sebum production (Strauss et al., 1962). Our observation that sebum production is not inhibited during pregnancy, at a time when oestrogens are being produced in quantities of the order of $200 \mathrm{mg}$. per day (of which $20 \mathrm{mg}$. is biologically active) (Fishman et al., 1962), means either that the effect of oestrogen on the sebaceous gland is blocked or that a powerful sebotrophic stimulus is produced during pregnancy. Our suggestion that the sebum excretion rate is in fact increased in pregnancy is more con- sistent with the presence of a sebotrophic factor. Owing to the complexity of the hormonal changes in pregnancy, and the lack of information of the effect of these hormones on sebaceous activity, the nature of the postulated sebotrophic stimulus is conjectural.

Thanks are due to Mr. Ian Cartwright for valuable technical assistance, and to the Research Committee of the Royal Victoria Infirmary, Newcastle upon Tyne, for a generous financial grant.

\section{REFERENCES}

Burton, J. L., Cunliffe, W. J., and Shuster, S. (1970). British Foumal of Dermatology. In press.

Cunliffe, W. J., and Shuster, S. (1969). British foumal of Dermatology, 81, 697.

Fishman, J., Brown, J. B., Hellman, L., Zumoff, B., and Gallagher, T. F. (1962) Fournal of Biological Chemistry, 237, 1489.

Strauss, J. S., Kligman, A. M., and Pochi, P. E. (1962). Foumal of Investigative Dermatology, 39, 139.

Strauss, J. S., and Pochi, P. E. (1961). Foumal of Investigative Dermatology, 36, 293.

Strauss, J. S., and Pochi, P. E. (1963). Advances in Biology of the Skin, 4, 220 .

\section{Medical Memoranda}

\section{Encapsulated Malrotated Midgut}

British Medical fournal, 1970, 2, 771-772

Malrotation of midgut is a fairly well known congenital anomaly, and may be the cause of colicky abdominal pains dating back to childhood. Few cases, however, have been recorded of an adult with a symptom-free childhood presenting with abdominal colic due to malrotation of midgut which was also encapsulated.

\section{CASE Report}

A 21-year-old man first complained in February 1968 of severe left-sided colicky abdominal pains. Occasionally these pains were accompanied by blackouts. On examination on 11 March nothing abnormal was found. He was asked to return in May. He was then still in pain, but gave the impression of being neurotic. An I.V.P. was normal. Barium meal examination showed that the duodenum, instead of curving round to the duodenojejunal flexure on the left of the body of L2, joined the jejunum on the right side of the abdomen (see Fig). The caecum was in the pelvis and the hepatic flexure was also extremely low in position.

At laparotomy the whole of the small intestine from the duodenojejunal flexure almost to the ileocaecal junction was found to be enclosed in a thin membranous transparent sac, and this was lying in the right upper quadrant. The caecum was in the right side of the pelvis and the hepatic flexure was very low in position. The mesentery was attached to the lower part of the ascending colon and caecum as well as the small intestine. It had no posterior attachment, and the small intestine had herniated through the hole behind the root of the mesentery to lie on the right side. This aperture was about $7.5 \mathrm{~cm}$. vertically and $5 \mathrm{~cm}$. anteroposteriorly.

The sac enclosing the small intestine was excised piecemeal. The small intestine was pulled back to the left through the hole behind the mesentery. The lie of the gut was normal. To prevent recurrence the posterior free border of the mesentery was sutured to the posterior parietal peritoneum. The patient made an uneventful recovery. When last seen in July 1969 he was symptomfree.

\section{COMMENT}

Malrotation of the gut is not unusual, but association with encapsulation seems to be rare. Devine (1932) described two male cases presenting with pictures of chronic intestinal obstruction. Both had intestines encapsulated by milky-white

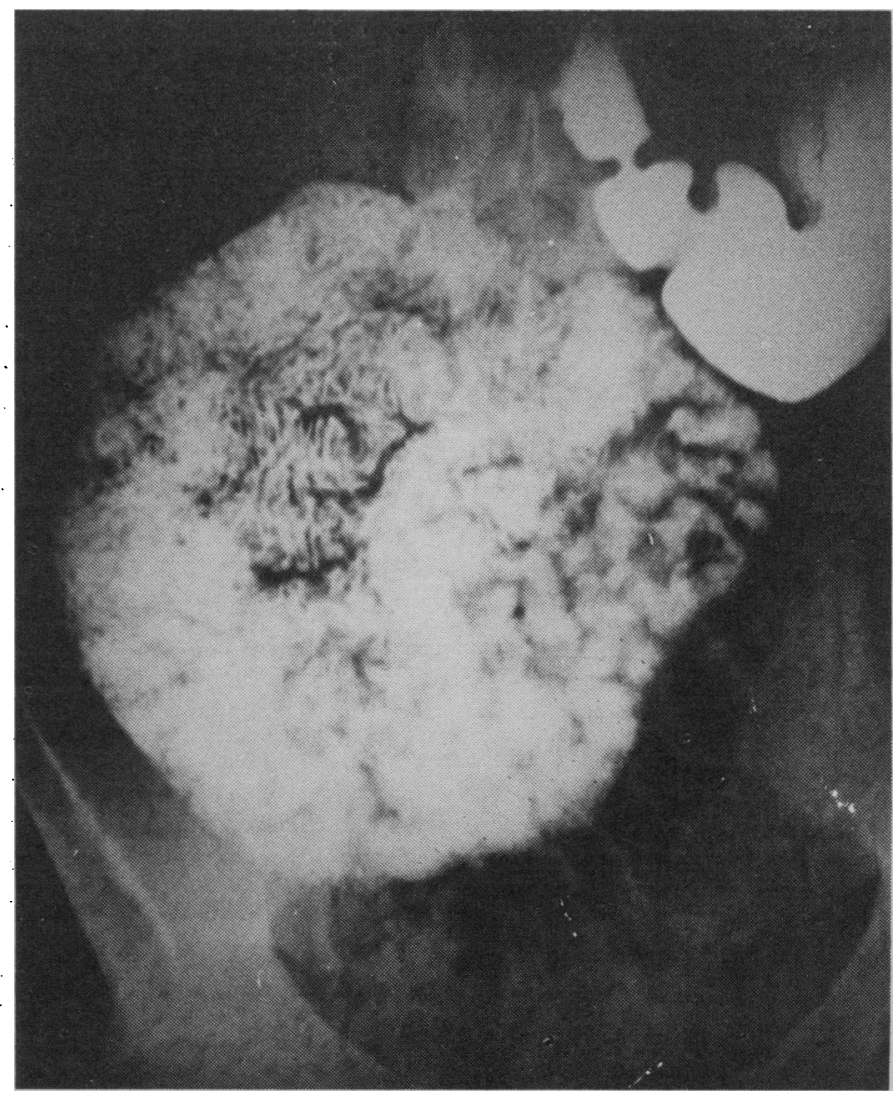

Barium meal and follow-through. The whole of the small intestine lies on the right side enclosed in one capsule.

membranes. Histology suggested they were due to chronic tuberculous peritonitis.

Devlin et al. (1968) gave a detailed description of five adults suffering from colicky abdominal pains dating back to 